\title{
A new parameter of geomagnetic storms for the severity of space weather
}

\author{
N. Balan ${ }^{1 *}\left(\mathbb{D}\right.$, I. S. Batista', S. Tulasi Ram² and P. K. Rajesh ${ }^{3}$
}

\begin{abstract}
Using the continuous Dst data available since 1957 and $H$ component data for the Carrington space weather event of 1859, the paper shows that the mean value of Dst during the main phase of geomagnetic storms, called mean Dst ${ }_{\mathrm{MP}}$ is a unique parameter that can indicate the severity of space weather. All storms having high mean $\mathrm{Dst}_{\mathrm{MP}}(\leq-250$ nT), which corresponds to high amount of energy input in the magnetosphere-ionosphere system in short duration, are found associated with severe space weather events that caused all known electric power outages and telegraph system failures.
\end{abstract}

\section{Background}

Geomagnetic storms are disturbances in earth's magnetic field produced by enhanced solar wind-magnetosphere coupling and ionosphere-magnetosphere plasma coupling (e.g., Svalgaard 1977; Gonzalez et al. 1994). Scientific analysis of geomagnetic storms lead to improved fundamental understanding of the earth's surrounding space weather environment (e.g., Prölss 2004; Kamide and Balan 2015). Applied analysis of the storms enables the assessment and mitigation of space weatherrelated hazards, for example, on satellite systems and orbits, satellite communication and navigation, overthe-horizon radio communication, geophysical surveys, electric power grids, and oil and gas metal pipe lines (e.g., Daglis 2004). Of particular concern are the effects associated with rare but extremely intense geomagnetic storms (e.g., Hapgood 2011; Cannon et al. 2013; Cliver and Dietrich 2013). A Carrington type event of 1859 (e.g., Carrington 1859) at present times, for example, can cause very serious social and economic impacts in the High-Tech society (e.g., Baker et al. 2008). It is therefore important for scientific and technological reasons to search for some parameter(s) of space weather events that can indicate their severity.

\footnotetext{
*Correspondence: balannanan@gmail.com

${ }^{1}$ Instituto Nacional de Pesquisas Espaciais, São Jose dos Campos,

SP 12227-010, Brazil

Full list of author information is available at the end of the article
}

The disturbance storm time (Dst) index (Sugiura 1964) represents geomagnetic storms. The intensity of the storms, which is the maximum negative value of Dst (or DstMin) during the storms, has conventionally been considered to represent the severity of space weather. However, recently by analyzing the Dst data since 1998, we (Balan et al. 2014) showed that DstMin is an insufficient indicator, and the mean value of Dst during the main phase (MP) of the storms (mean Dst ${ }_{\mathrm{MP}}$ ) can indicate the severity of space weather in causing damages to technological systems such as electric power grids and telegraph systems. In this paper, using all the Dst data available since 1957 and $H$ component data during the Carrington event of 1859 , we confirm that the mean Dst ${ }_{\mathrm{MP}}$ is a unique parameter that can indicate the serenity of space weather.

\section{Dst data and analysis}

We use the hourly Dst data of $1 \mathrm{nT}$ resolution for 58 years available at Kyoto WDC since 1957, with no data gaps and no erroneous values (http://swclob-kugi.kyoto-u. ac.jp). The Dst index is obtained from the horizontal $H$ component measured at four low-latitude stations (3 in north and 1 in south) outside the equatorial electrojet belt (Sugiura 1964; Sugiura and Kamei 1991). A disturbance time series is estimated for each station by subtracting a non-storm quiet time baseline; and the Dst time series is obtained as an average of the individual disturbance time series from the four stations. For the 
Carrington storm of September 1859, we use the $H$ range data measured at Mumbai and reported by Tsurutani et al. (2003). H range is similar to Dst but positive. For consistency, we take $H$ range also as negative like Dst.

The Dst storms are identified by developing a computer program which minimizes non-storm like fluctuations and avoids human errors. Figure 1, for example, illustrates the procedure. The program first detects the negative slopes in the Dst variation (green dots, Fig. 1a) and identifies the preliminary main phase onsets (MPOs) when Dst starts decreasing (red starts) and DstMin when Dst reaches maximum negative values (black stars, Fig. 1b). The program then applies the selection criterion (1) DstMin $\leq-50 \mathrm{nT}$ and MP duration $>2 \mathrm{~h}$, and criterion (2) absolute value of MP range, that is, IDst $_{\text {MPO }}-$ DstMinI $\geq 50 \mathrm{nT}$. By applying criteria (1) and (2), many short-period, non-storm like negative fluctuations of Dst are eliminated (Fig. 1c). With a view to further avoid the short-period positive deflections during MP and identify clearly separated storms, the criterion (3), that is, separation between DstMin and next MPO $>6 \mathrm{~h}$, is applied. Further to avoid very slowly varying, non-storm like long duration decreases in Dst, the criterion (4), that is, rate of change of Dst during MP or $(\mathrm{dDst} / \mathrm{dt})_{\mathrm{MP}}<-5 \mathrm{nT} / \mathrm{h}$, is applied, which results in the detection of the clear storm in Fig. 1d. By applying the procedure to the whole Dst data, the computer program identified 810 storms which

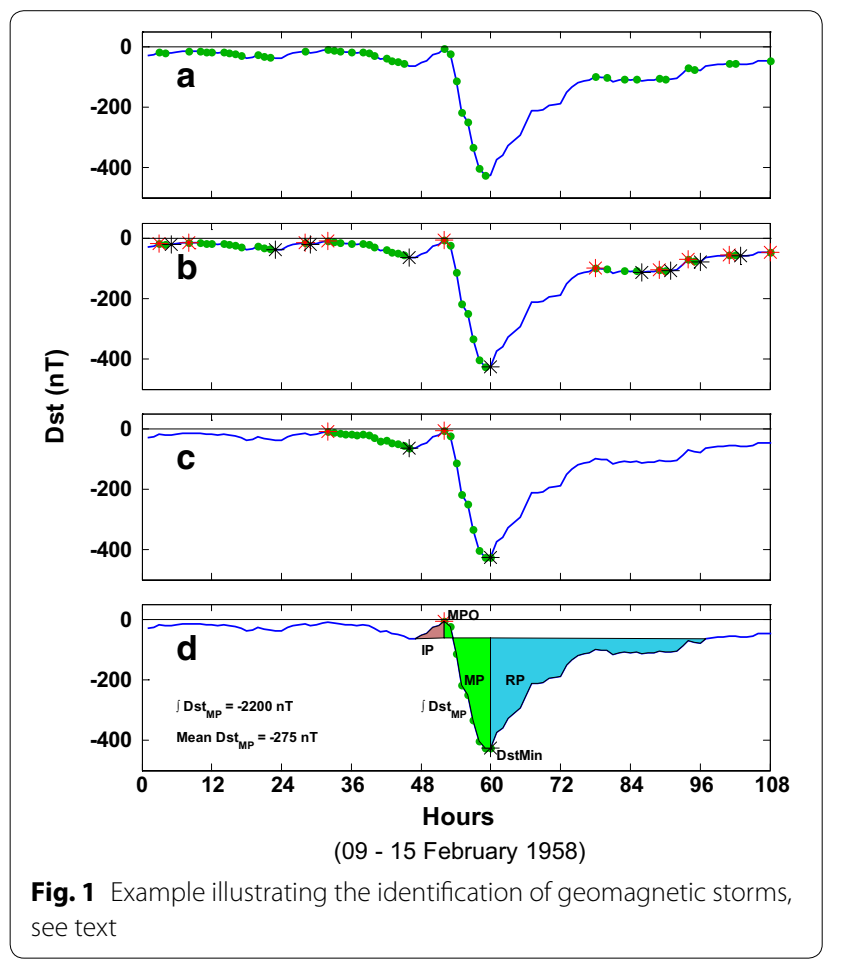

include 365 intense storms (DstMin $\leq-100 \mathrm{nT}$ ) and 39 super storms (DstMin $\leq-250 \mathrm{nT}$ ).

The estimation of the storm parameters are illustrated using Fig. 1d which also shows the storm phases. The impact at the Earth of a coronal mass ejection (CME) compresses the dayside magnetopause, intensifies its eastward directed current, and generates a positive perturbation in Dst, known as initial phase (IP) which usually lasts from tens of minutes to a few hours. It may be noted that IP is not well identifiable in all storms. This is followed by the main phase (MP) when the field decreases due to the enhancement of the westward ring current, which begins with the southward turning of IMF (interplanetary magnetic field) $\mathrm{Bz}$ and consequent solar wind-magnetosphere coupling and loading of solar wind energy into the ring current; it lasts for several hours to over ten hours when IMF $\mathrm{Bz}$ remains southward. When IMF Bz returns to zero or turns northward, the solar wind forcing diminishes, ring current intensity eventually dissipates, and Dst recovers back to its near-zero prestorm level recovery phase (RP) usually taking tens of hours to several days.

The storms are analyzed for their important parameters. Main phase duration $\mathrm{T}_{\mathrm{MP}}$ is the time interval between MPO and DstMin which are defined above and identified in Fig. 1d; UT hours of MPO and DstMin are noted. $\int D^{2} t_{M P}$ is the integral (or sum) of Dst during MP. For storms with positive initial phase, it is the negative of the sum of the magnitudes of Dst from MPO to DstMin. Mean Dst ${ }_{\mathrm{MP}}=\int \mathrm{Dst}_{\mathrm{MP}} / T_{\mathrm{MP}}$ is the new parameter which indicates the strength of geomagnetic storms while DstMin represents their intensity, discussed in "Results and discussion" section. $\left(\mathrm{dDst}_{\mathrm{MP}} / \mathrm{d} t\right)_{\max }$ is the maximum rate of change of Dst during MP, which is the maximum successive difference of Dst during MP.

\section{Results and discussion}

Although over 800 storms are identified, we consider the 39 super storms (DstMin $\leq-250 \mathrm{nT}$ ) and the Carrington storm because storms weaker than super storms are unlikely to be associated with system damages (e.g., Baker et al. 2008; Balan et al. 2014). The characteristics of the storms such as date of DstMin, value of DstMin, time of MPO, time of DstMin, MP duration, mean Dst ${ }_{\mathrm{MP}}$, and $\left(\mathrm{dDst}_{\mathrm{MP}} / \mathrm{d} t\right)_{\max }$ are listed in Table 1 . The solar activity index (F10.7) is also listed.

Figure 2 displays the characteristics of all 40 super storms arranged in the order of decreasing mean Dst ${ }_{\mathrm{MP}}$. For clarity, the scales of mean Dst ${ }_{\mathrm{MP}},\left(\mathrm{dDst}_{\mathrm{MP}} / \mathrm{d} t\right)_{\max }$, and DstMin are limited. Purple color represents the storms associated with severe space weather (SvSW) events that caused electric power outages and/or telegraph system 
Table 1 Characteristics of geomagnetic storms (DstMin $\leq-250 \mathrm{nT}$ )

\begin{tabular}{|c|c|c|c|c|c|c|c|}
\hline No & Date & DstMin (nT) & T1-T2 (UT h) & MPD (hr) & Mean Dst $_{\text {MP }}(\mathrm{nT})$ & $\mathrm{dDst}_{\mathrm{MP}} / \mathrm{dt}(\mathrm{nT} / \mathrm{h})$ & Daily 10.7 \\
\hline 1 & 1859-09-01 & -1710 & 05-07 & 2 & -700 & 1390 & - \\
\hline 2 & 1989-03-13 & -589 & $14-02$ & 12 & -357 & 111 & 253 \\
\hline 3 & 1958-02-11 & -426 & $04-12$ & 8 & -275 & 103 & 224 \\
\hline 4 & 2001-11-06 & -292 & $02-07$ & 5 & -259 & 168 & 233 \\
\hline 5 & 2003-10-30 & -383 & $18-23$ & 5 & -258 & 98 & 268 \\
\hline 6 & 1957-09-05 & -324 & $14-04$ & 14 & -239 & 90 & 241 \\
\hline 7 & 2001-03-31 & -387 & 04-09 & 5 & -238 & 148 & 245 \\
\hline 8 & 1981-04-13 & -311 & 00-07 & 7 & -235 & 75 & 255 \\
\hline 9 & $1967-05-26$ & -387 & $17-05$ & 12 & -230 & 106 & 219 \\
\hline 10 & 2004-11-10 & -263 & $02-11$ & 9 & -229 & 43 & 103 \\
\hline 11 & $1989-10-21$ & -268 & $06-17$ & 11 & -220 & 61 & 206 \\
\hline 12 & 1960-04-01 & -327 & $10-19$ & 9 & -217 & 56 & 201 \\
\hline 13 & 1957-09-13 & -427 & $02-11$ & 9 & -216 & 122 & 272 \\
\hline 14 & 2004-11-08 & -374 & 20-07 & 11 & -209 & 96 & 122 \\
\hline 15 & 2003-11-20 & -422 & $09-21$ & 12 & -204 & 100 & 171 \\
\hline 16 & 1959-07-15 & -429 & $09-20$ & 11 & -204 & 92 & 253 \\
\hline 17 & 1958-09-04 & -302 & $14-23$ & 9 & -201 & 55 & 261 \\
\hline 18 & 1991-10-29 & -254 & $23-08$ & 9 & -188 & 29 & 269 \\
\hline 19 & 1991-11-09 & -354 & $14-02$ & 12 & -187 & 63 & 194 \\
\hline 20 & 1960-04-30 & -325 & 13-19 & 6 & -184 & 151 & 164 \\
\hline 21 & 2000-04-06 & -288 & $17-01$ & 8 & -183 & 74 & 178 \\
\hline 22 & 2003-10-29 & -353 & 07-01 & 18 & -179 & 95 & 275 \\
\hline 23 & 1989-11-17 & -266 & $10-23$ & 13 & -179 & 52 & 215 \\
\hline 24 & 1982-09-06 & -289 & $00-12$ & 12 & -175 & 44 & 172 \\
\hline 25 & 2000-07-15 & -301 & $16-01$ & 9 & -172 & 137 & 220 \\
\hline 26 & 1958-07-08 & -330 & $10-23$ & 13 & -170 & 92 & 240 \\
\hline 27 & $1982-07-14$ & -325 & $17-02$ & 9 & -163 & 110 & 269 \\
\hline 28 & $1991-03-25$ & -298 & $15-01$ & 10 & -157 & 63 & 235 \\
\hline 29 & 1970-03-08 & -284 & $15-23$ & 8 & -156 & 90 & 173 \\
\hline 30 & $1961-10-28$ & -272 & $10-19$ & 9 & -154 & 62 & 86 \\
\hline 31 & 2001-04-11 & -271 & $16-24$ & 8 & -145 & 58 & 160 \\
\hline 32 & $1960-11-13$ & -339 & $17-10$ & 17 & -142 & 81 & 178 \\
\hline 33 & $1957-09-23$ & -303 & $11-07$ & 45 & -138 & 65 & 297 \\
\hline 34 & 1990-04-10 & -281 & 23-19 & 20 & -133 & 45 & 149 \\
\hline 35 & 1960-10-07 & -287 & $21-01$ & 28 & -120 & 45 & 145 \\
\hline 36 & $1957-01-21$ & -250 & $14-23$ & 9 & -116 & 80 & 219 \\
\hline 37 & 1992-05-10 & -288 & $21-15$ & 18 & -111 & 62 & 127 \\
\hline 38 & 1989-09-19 & -255 & $15-05$ & 14 & -106 & 40 & 197 \\
\hline 39 & 1986-02-08 & -307 & 04-01 & 45 & -105 & 72 & 94 \\
\hline 40 & 1957-03-02 & -255 & $21-08$ & 11 & -83 & 100 & 180 \\
\hline
\end{tabular}

Date is of DstMin. T1 and T2 are times of MPO and DstMin. MPD is MP duration. F10.7 is on the day of DstMin

failures; and blue color corresponds to normal space weather (NSW) events that did not cause such damages, discussed below. The unique parameter that distinguishes SvSW and NSW events is the mean Dst ${ }_{\text {MP }}$ (panel a). All five storms associated with SvSW events (purple color) have mean Dst $_{M P} \leq-258 \mathrm{nT}$ and all remaining 35 storms associated with NSW events have mean Dst $_{\mathrm{MP}} \geq-238$
nT. Also, 20 of the storms associated with NSW events have lower DstMin (as low as $-429 \mathrm{nT}$ ) than the highest DstMin corresponding to SvSW events (panel c). Although $\left(\mathrm{dDst}_{\mathrm{MP}} / \mathrm{d} t\right)_{\max }$ (panel b) is high $(>95 \mathrm{nT} / \mathrm{h})$ for SvSW events, it does not distinguish SvSW and NSW events because $8 \mathrm{NSW}$ events have higher value for the parameter than the lowest value associates with SvSW 

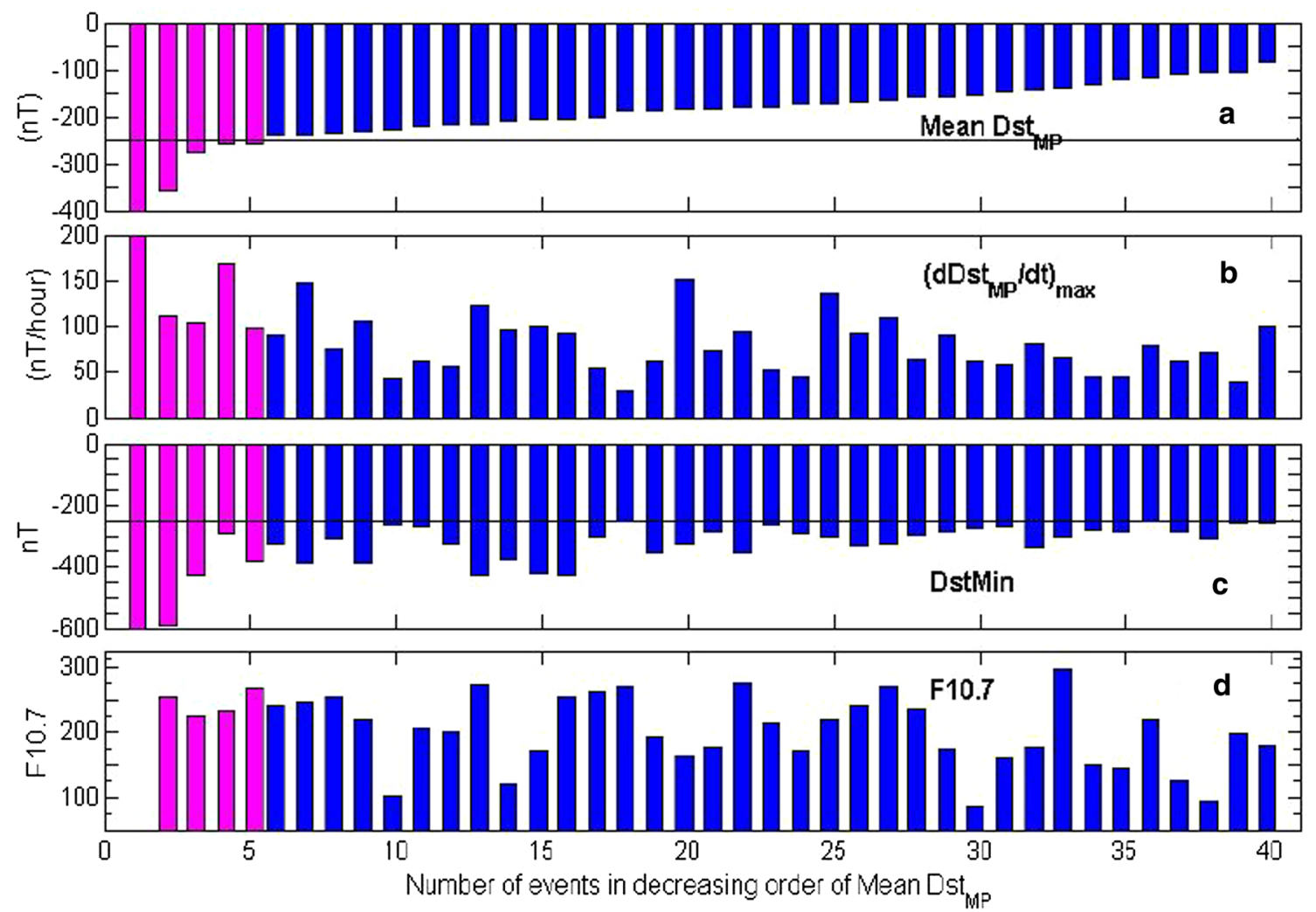

Fig. 2 Parameters of super storms (mean Dst $\mathrm{MP}_{\text {, }}\left(\mathrm{dDst}_{\mathrm{MP}} / \mathrm{dt}\right)_{\max }$ and DstMin) and solar activity index $\mathrm{F} 10.7$ arranged in the order of decreasing mean Dst $_{M P}$

events. While all 5 super storms associated with SvSW events occurred under high solar activity (F10.7 >225), the storms in general are independent of solar activity (panel d). Mean Dst ${ }_{M P}(\leq-250 \mathrm{nT})$ therefore is a unique parameter of geomagnetic storms that can indicate the severity of space weather while the conventional parameter DstMin is insufficient.

The most famous severe space weather event (Carrington 1859) caused telegraph system failures (event 1, Fig. 2) and produced the most extreme geomagnetic storm in known history (Tsurutani et al. 2003) with highest values of mean Dst ${ }_{\text {MP }}(-700 \mathrm{nT})$ and DstMin $(-1710$ nT) though Akasofu and Kamide (2005) commented that such extremely high value of Dst is unrealistic. The famous electric power outage in Quebec on March 13, 1989 (e.g., Medford et al. 1989) is associated with an extreme storm (event 2) of mean Dst ${ }_{\mathrm{MP}}<-350 \mathrm{nT}$. The SvSW event on February 11, 1958 (event 3), which caused fire and severe damages in the telegraph systems in Sweden (e.g., Wik et al. 2009), also produced an extreme storm (mean Dst ${ }_{\mathrm{MP}}=-275 \mathrm{nT}$ ). The SvSW events on Nov 06, 2001 and Oct 30, 2003 (events 4 and 5) caused power outages in New Zealand (Marshall et al. 2012) and Sweden (e.g., Wik et al. 2009) and produced extreme storms (mean Dst $_{\mathrm{MP}}<-255 \mathrm{nT}$ ).

High value of the unique parameter mean Dst $_{M P}$ corresponds to high $\int \mathrm{Dst}$ occurring in short duration MP. For example, the most famous SvSW event has the highest $\int$ Dst (or $\int H$ ) occurring in the shortest MP of duration only about $2 \mathrm{~h}$. Such storms are produced by CMEs having high front velocity $\Delta V$ (sudden increase over the background) and sufficiently large IMF $\mathrm{Bz}$ southward at the front (Balan et al. 2014). The physics of high mean Dst ${ }_{M P}$ therefore seems high amount of energy input into the magnetosphere-ionosphere system in short duration probably through continuous and rapid magnetic reconnection (e.g., Borovsky et al. 2008), so that the system responds impulsively. The impulsive response causes strong electric currents in the ionosphere especially at high latitudes, which, in turn, leads to technological system damages through secondary electrical induction on ground systems.

\section{Conclusions}

High value of mean Dst during the main phase of geomagnetic storms (Dst ${ }_{\mathrm{MP}} \leq-250 \mathrm{nT}$ ), which represents 
high amount of energy input in the magnetosphereionosphere system in short duration, corresponds to the severe space weather events that caused all known electric power outages and telegraph system damages. The information can help identify the characteristic parameter of SvSW in other geophysical data and in the design of technological systems.

\section{Author details}

${ }^{1}$ Instituto Nacional de Pesquisas Espaciais, São Jose dos Campos, SP 12227-010, Brazil. ${ }^{2}$ Indian Institute of Geomagnetism, Navi Mumbai, India.

${ }^{3}$ National Cheng Kung University, Tainan, Taiwan.

\section{Acknowledgements}

We thank the Kyoto WDC for the Dst data (http://wdc.kugi.kyoto-u.ac.jp/ dstdir/). N Balan thanks CNPq of Brazil for an Invitation Fellowship.

\section{Competing interests}

The authors declare that they have no competing interests.

Received: 22 December 2015 Accepted: 1 February 2016

Published online: 19 February 2016

\section{References}

Akasofu SI, Kamide Y (2005) Comments on the extreme magnetic storm of 1-2 September 1821859 by B. T. Tsurutani, W. D. Gonzalesz, G. S. Lakhina and S. Alex. J Geophys Res 110, A09226, doi:10.1029/2005JA011005

Baker DN et al (2008) Severe space weather events—understanding societal and economic impacts. The National Academy Press, Washington DC, pp $1-144$

Balan N, Skoug R, Tulasi Ram S, Rajesh PK, Shiokawa K, Otsuka Y, Batista IS, Ebihara Y, Nakamura T (2014) CME front and severe space weather. J Geophys Res Space Phys. doi:10.1002/2014JA020151
Borovsky JE, Hesse M, Birn J, Kuzentsova MM (2008) What determines the reconnection rate at the dayside magnetosphere? J Geophys Res 113:A07210. doi:10.1029/2007JA012645

Cannon P et al (2013) Extreme space weather: impacts on engineered systems and infrastructure. Royal Academy of Engineering, London, pp 1-68

Carrington RC (1859) Description of a singular appearance seen in the Sun on, 1859. Mon Not R Astron Soc 20:13-15

Cliver EW, Dietrich WF (2013) The 1859 space weather event revisited: limits of extreme activity. J Space Weather Space Clim 3:A31. doi:10.1051/ swsc/2013053

Daglis IA (ed) (2004) Effects of space weather on technology infrastructure. Kluwer Academic, Dordrecht, pp 1-334

Gonzalez WD, Joselyn JA, Kamide Y, Kroehl HW, Rostoker G, Tsurutani BT, Vasyliunas VM (1994) What is a geomagnetic storm? J Geophys Res 99:5771

Hapgood MA (2011) Towards a scientific understanding of the risk from extreme space weather. Adv Space Res 47:2059-2072

Kamide Y, Balan N (2015) The importance of ground magnetic data in specifying the state of magnetosphere-ionosphere coupling: an historical account. Geosci lett

Marshall RA, Dalzell M, Waters CL, Goldthorpe P, Smith EA (2012) Geomagnetically induced currents in the New Zealand power network. Sp Weather 10:S08003. doi:10.1029/2012SW000806

Medford et al (1989) Transatlantic earth potential variations during the March 1989 magnetic storms. Geophys Res Lett 16(10):1145

Prölss GW (2004) Physics of the earth's space environment. Springer, Berlin, pp $1-513$

Sugiura M (1964) Hourly values of equatorial Dst for the IGY. Ann Int Geophys Yr 35:9-45

Sugiura M, Kamei T (1991) Equatorial Dst index 1957-1986, IAGA Bull. vol 40. ISGI Pub Office, Saint-Maur-des-Fossess

Svalgaard L (1977) Geomagnetic activity: dependence on solar wind parameters. In: Zirker JB (ed) Coronal holes and high speed wind streams. Colorado Association University Press, Boulder, pp 371-441

Tsurutani BT, Gonzalez WD, Lakhina GS, Alex S (2003) The extreme magnetic storm of 1859. J Geophys Res 108:1268-1275

Wik M, Pirjola R, Lundstedt H, Viljanen A, Wintoft P, Pulkkinen A (2009) Space weather events in July 1982 and October 2003 and the effects of geomagnetically induced currents on Swedish technical systems. Ann Geophys 27:1775-1787

\section{Submit your manuscript to a SpringerOpen ${ }^{\odot}$ journal and benefit from:}

- Convenient online submission

- Rigorous peer review

- Immediate publication on acceptance

- Open access: articles freely available online

- High visibility within the field

- Retaining the copyright to your article

Submit your next manuscript at $>$ springeropen.com 